\title{
A Look at Unsociability on Facebook
}

\author{
Marisela Gutierrez Lopez Saila Ovaska \\ School of Information Sciences, University of Tampere \\ Kanslerinrinne 1, 33014 Tampereen yliopisto, Finland \\ marisela.gtz@gmail.com_Saila.Ovaska@uta.fi
}

\begin{abstract}
We propose unsociability as a novel perspective to approach and support online social interactions. With examples taken from focus group discussions, we highlight the need of users to save face in their online interactions within social network sites. We claim that people follow a "social-over-technical" pattern on Facebook, as they base their interactions on their social understanding of this site instead of on its technical capabilities. These social norms and patterns challenge social translucence which has for more than a decade been recognized as one of the cornerstones of social computing systems.
\end{abstract}

Social network sites; features; unsociability; design.

\section{INTRODUCTION}

Contrary to real life where one cannot simply "reverse" social interactions, some social network sites (SNSs) allow people to "go backwards" or take a step back in order to limit social interactions. Linguist analysis suggests that the prefix "un-" used to name some SNSs' features originates as an analogy for the "undo" functionality of computer programs (Zimmer 2009).

For instance, Mary can use the Unfriend feature of Facebook to delete her connection with Tim, returning to a system state where she did not have Tim in her virtual social network (Figure 1, step 2). We argue, in this context, that Mary's behaviour is "unsocial", taking back some part of the social interaction that has occurred between them.

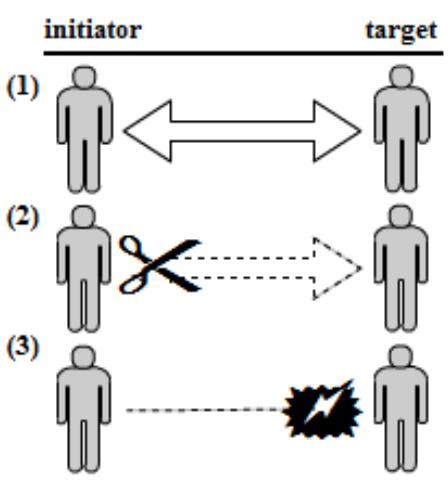

Figure 1: The dynamic of an unsocial event.

Moreover, while Facebook does not actively notify users about unsocial behaviours, there are subtle, yet present, cues for a person to figure out that they have been involved in such event. We call these the awareness cues (Figure 1, step 3). For instance, Tim may notice that he does no longer have Mary listed as his Friend, and infer that she deleted their mutual connection.

As we will point out, unfriending is only the tip of the iceberg. Based on focus group findings, we will discuss several other SNS features which allow users to reverse or limit social interactions when applied in "unsocial" behaviours, and explain how these features are considered "hard" or "soft" on the social relations that are targeted, depending on the awareness cues presented in the interface to the target of the act.

We believe this mechanism of "backward" sociality is fundamental to exploring the full spectrum of online interactions. Though much work has been directed towards so called "avoidance strategies" (Canary et al. 1993), our approach extends on those with a practical twist towards the actual behaviours in unsocial events. As can be seen in Figure 1, unsocial events include two users who are directly involved in the unfriending action. It is equally important to study both sides, and not just the avoidance strategies or privacy and selfpresentation concerns of the initiator.

It is important to note that unsocial and antisocial behaviours are not the same. A common connotation of antisocial behaviours involves action against the law or society (Oxford Dictionaries 2013a), as in online bullying or scams. Unsocial behaviours, as considered in this study, are ways of social interaction between two persons that have no society-wide negative connotations. Being unsociable is "not enjoying or making an effort to behave sociably in the company of others" (Oxford 
Dictionaries 2013b). This kind of behaviour is part of life and not extreme in any sense. We consider unsocial and unsociable synonyms, but unsocial behaviour can be less than being unsociable: it points at personal preferences, not hostility.

Our paper is structured as follows. In the Background section, we build an understanding of unsociability. Then, our data collection and analysis methods are detailed. In the Results section, we offer explanations for the social-over-technical pattern in Facebook use, and the implications for this pattern are brought up in Discussion. Finally, we present design implications.

\section{BACKGROUND}

By nature, people tend to maintain private spaces (Altman 1977). SNSs are about connecting people in networked spaces, yet it is not realistic to assume that everybody wants to share everything, with everyone, all the time (Lampinen et al. 2011).

Privacy is a dynamic "boundary control" process (Altman 1977). According to Johnson et al. (2012), Facebook offers useful privacy controls for users to mitigate their privacy concerns over sharing content with strangers. Nevertheless, Facebook controls do not mitigate "inside threats", such as having Friends from conflicting social spheres. Therefore, persons use several "ad hoc" techniques, such as self-censorship and segregating audiences, to maintain their privacy boundaries (Johnson et al. 2012) and to manage their self-presentation (Lampinen et al. 2011).

People try to present themselves and their social interactions over SNSs in the most positive light possible (Lampinen et al. 2011; Zhao et al. 2008). Much as in real life, people try to "save face" (Goffman 1967) while interacting on SNSs or other CMC tools (Aoki and Woodruff 2005; Bryant and Marmo 2012; Hancock et al. 2009; Lampinen et al. 2011). The measures taken to do things consistent with face are called "face-work" (Goffman 1967). Face-work is useful for maintaining harmonious relations and avoiding awkward or embarrassing situations.

Face-work is regarded as an important concern for users of SNSs, as the interactions take place in a public setting and are ruled by social norms (Bryant and Marmo 2012). More important, persons hold accountability for their online actions (Bryant and Marmo 2012; Lampinen et al. 2011; Zhao et al. 2008). Therefore, users may be reluctant to engage in potential face-threatening behaviours, such as Unfriend (Bevan et al. 2012; Bryant and Marmo 2012), for normative reasons. Instead, users may prefer to find more polite ways to avoid contact.

Canary et al. (1993) proposed a typology of ten strategies that play a role in maintaining different types of relationships. We find that their avoidance strategy is in line with being unsocial, as these behaviours are used to evade another person or issue attempting to prevent a relation from escalating. Thus, avoidance strategy (Canary et al. 1993) is a natural start point of our research. Nevertheless, by definition, avoidance behaviours maintain a relation. Unsocial event mediated by the SNS is a special case: it involves two persons and is based on the features available in the system; it can also extend to breaking a relation, not only maintaining it at a distance.

Bryant and Marmo (2010) associated seven behaviours with the avoidance strategy on Facebook: removing users from one's network on the site, rejecting Friend Requests, blocking or reporting people, adding people under a restricted profile, using Facebook so as to avoid giving out personal information, intentionally not responding to messages, and avoiding a chat request by ignoring people or logging off.

Only some of these seven avoidance behaviours clearly involve action. For example, users have to click (action) Unfriend (feature) to remove a person (behaviour). Not responding to messages is an absence of action. We group avoidance behaviour whose essence is non-action under the concept of "unresponsiveness," roughly as suggested by Aoki and Woodruff (2005). These behaviours still fit the definition of unsocial events though not associated with particular functionality, since they are deliberate acts to elude another person by consciously avoiding use of the features to reciprocate the interaction.

Extending on these concepts introduced in previous work, the present study has two objectives. First, we want to find out which behaviour can be considered as unsocial, as well as how users select which SNS feature to use in them. Second, we study how users perceive unsocial events, the features in question, and the outcome of their usage expecting to shed light on the users' concerns of self-presentation and privacy.

\section{METHODS}

First we explain our methods for relating the avoidance behaviour types to functionality that can be used in these acts. Then we describe the focus groups, the interview protocol, and our recruitment of participants.

\subsection{Linking avoidance behaviours and system features}

We are interested in finding out which features are associated to avoidance behaviour. To avoid biasing the study with our own understanding of the 
SNS features, we referred to the Help and FAQ (Frequently Asked Questions) sections of Facebook for the recommended feature to be used for each avoidance behaviour. For instance, we queried on Facebook's Help Centre: "how to remove a Friend." Finally, those features that appeared most likely to be used are named as the "anticipated" unsocial features, summarized in Table 1.

Table 1: Anticipated unsocial features for Facebook, and the five scenarios (verbatim).

\begin{tabular}{ll}
\hline $\begin{array}{l}\text { Anticipated } \\
\text { feature }\end{array}$ & Scenario \\
\hline Unfriend & $\begin{array}{l}\text { She wants to dissolve the connection with one } \\
\text { of her contacts }\end{array}$ \\
\hline $\begin{array}{l}\text { Not Now/ } \\
\text { Delete } \\
\text { Request }\end{array}$ & She wants to reject a connection request \\
\hline $\begin{array}{l}\text { Report/ } \\
\text { Block }\end{array}$ & $\begin{array}{l}\text { She wants to prevent one person from } \\
\text { contacting her online }\end{array}$ \\
\hline Unsubscribe & $\begin{array}{l}\text { She wants to hide the posts of one of her } \\
\text { contacts }\end{array}$ \\
\hline Lists & $\begin{array}{l}\text { She does not want to share her posts with one } \\
\text { of her contacts }\end{array}$ \\
\hline
\end{tabular}

For stimulating discussion among the focus group participants, we generated five scenarios based on the avoidance behaviours (Bryant and Marmo 2010). The scenarios listed in Table 1 were in the form of problem statements. Further details on how this was addressed in the focus groups are given in the next subsections.

Facebook constantly modifies its features. As new features are implemented, previous ones may no longer be available with the same name or functionality. For that reason, this section (and the study in general) is intended to be not an exhaustive review of Facebook features but an overview of how SNSs support unsocial behaviour and how that behaviour manifests itself.

\subsection{Focus group interviews}

Focus groups are useful in helping people express their opinions by talking to peers about them and in creating mutual understanding within a social context (Stewart et al. 2007). However, special attention had to be given to the interview protocol in order to make focus groups a suitable method for this study.

We generated a semi-structured protocol of 12 questions and supplementary visual materials. The interview protocol was divided into two parts: a structured overview of features to use, and perceptions of being involved in an unsocial event.

For the features part, participants were introduced to the scenarios of Table 1 one by one and asked to advise a hypothetical friend on how to resolve the situation.
To help participants recall the features and how they work, we prepared a set of printouts with screenshots, from made-up profiles, of the anticipated features for each scenario presented in Table 1. We explained that the printouts presented correspond to the feature that Facebook suggested the friend use in each situation but that the participants, as experienced users, could give her better advice.

For the perceptions part, participants were asked for their personal experiences when handling unsocial events. With questions such as "what cues made you notice that an unsocial feature was used on you?" we gathered data on the perceptions of these behaviours.

\subsection{Participants}

We sought volunteers to join the groups via local email lists and online forums. The only recruitment criterion was active membership (login at least once a week) to Facebook. No personal characteristics such as technical knowledge or age group were considered in screening the participants as we expected the sample to include people from a variety of backgrounds.

Demographic and SNSs usage information was gathered using an online questionnaire. Four groups were formed (see Table 2) of 10 Facebook users. The sample, seven males and three females ranging between 18 and 49 years, consisted of people from seven countries. Eight participants login on Facebook on a daily basis, while two do it on a weekly basis. The participants are welleducated, and seven of them study or work in a technology-related field.

One face-to-face session was conducted with each group in a comfortable, yet controlled environment. The settings of the rooms were arranged with participants seated face-to-face to promote interaction. All groups were audio and video recorded.

Table 2: Focus groups.

\begin{tabular}{cccc}
\hline Group & $\begin{array}{c}\text { Number of } \\
\text { participants }\end{array}$ & $\begin{array}{c}\text { Duration } \\
\text { in minutes }\end{array}$ & $\begin{array}{c}\text { Participants and their } \\
\text { Facebook contacts }\end{array}$ \\
\hline Group 1 & 3 & 100 & $\begin{array}{c}\text { P1: } 101-150 \\
\text { P2: } 201-300 \\
\text { P3: } 401-450\end{array}$ \\
\hline Group 2 & 2 & 86 & $\begin{array}{c}\text { P4: } 101-150 \\
\text { P5: } 1-100\end{array}$ \\
\hline Group 3 & 2 & 76 & $\begin{array}{c}\text { P6: } 1-100 \\
\text { P7: } 451-\end{array}$ \\
Group 4 & 3 & \multirow{2}{*}{101} & $\begin{array}{c}\text { P8: } 251-300 \\
\text { P9: } 451-\end{array}$ \\
& \multirow{2}{*}{3} & & P10: $251-300$
\end{tabular}

All groups were moderated by the first author. To address possible unpleasantness on sensible issues, none of the participants were forced to 
answer the entirety of the questions. No monetary incentives were given to the volunteers.

\subsection{Data analysis}

After the sessions, full transcripts were made from the audio of the sessions. Subsequently, we examined the discussion transcript by applying content analysis techniques (Stewart et al. 2007) to explore various levels, such as groups, individuals, and utterances, searching for recurrent words, topics, and discourses. Content is reported by means of direct quotations where appropriate. Since the data set is small, no statistical analysis techniques were employed in the analysis.

\section{RESULTS}

At the outset of our study, we made a first approach to unsocial behaviours by making assumptions about what features support them (cf. Table 1). However, they were not fully supported by the data and indeed turned out to be incomplete. For instance, some participants avoid action altogether, or suggest using Privacy Settings, while we had not previously considered it as an unsocial feature. Table 3 summarizes the Facebook features that were brought up by participants as options to consider in each scenario.

The features we had anticipated were not clearly linked to the corresponding scenario in the focus group discussions. The reason for this was that participants focused on their social understanding of the features, not on technical capabilities of the functionality; this we call the social-over-technical pattern of unsociability on Facebook.

\subsection{Social-over-technical pattern}

An example of the social-over-technical pattern is what most participants described as graded "steps" for avoiding people. Participants used different features, with dissimilar technical capabilities, for achieving the same end: keeping another person away. They described, as illustrated in Excerpt 1, that the first step for gaining distance from another person is to use Unfriend. If this fails, the second step would be to use Report/Block.

P4: I would say if it's not harassment, Unfriend would be like OK [...]. Maybe Unfriend would be the first step. And then, if the person has more things to do, then maybe Block. I mean, both options are fine; in my opinion, they are like steps. [Excerpt 1, Group 2]

The seven participants who mentioned being familiar with the fairly new feature Unsubscribe described it as the first step for avoiding somebody. Unsubscribe was preferred over Unfriend and, as illustrated in Excerpt 2, over Report/Block.

P3: I use Unsubscribe, not blocking people. [Excerpt 2, Group 1]

That is, even though the technical capabilities of Unfriend, Unsubscribe, and Report/Block differ, participants linked them together under the same discourse.

These steps described by the participants lead us to believe that it is not only the technical capabilities but also the users' perceptions of them that determine the usefulness of unsocial features. Before considering the technical affordances (boyd 2010), participants evaluated their social understanding in order to decide whether to use the system features.

In other words, those participants who considered deleting connections rude explained they avoid using Unfriend, so that others will not perceive them as being rude. Instead, these participants mentioned they adapt the system into their needs by using another feature, such as Unsubscribe, or simply preferred to avoid action to evade social costs.

Table 3: Scenarios linked with action avoidance and Facebook features, categorized into soft and hard unsocial features.

\begin{tabular}{|c|c|c|c|c|c|c|c|}
\hline \multirow[b]{2}{*}{ Scenario } & \multicolumn{3}{|c|}{ Soft unsocial features } & \multicolumn{3}{|c|}{ Hard unsocial features } & \multirow{2}{*}{$\begin{array}{l}\text { Avoiding action } \\
\text { Leave pending/ } \\
\text { do nothing }\end{array}$} \\
\hline & Unsubscribe & Lists & $\begin{array}{l}\text { Privacy } \\
\text { Settings }\end{array}$ & Unfriend & $\begin{array}{l}\text { Report/ } \\
\text { Block }\end{array}$ & $\begin{array}{l}\text { Not Now/ } \\
\text { Delete } \\
\text { Request }\end{array}$ & \\
\hline $\begin{array}{l}\text { She wants to } \\
\text { dissolve the } \\
\text { connection with one } \\
\text { of her contacts }\end{array}$ & $\checkmark$ & & & $\checkmark$ & $\checkmark$ & & $\checkmark$ \\
\hline $\begin{array}{l}\text { She wants to reject a } \\
\text { connection request }\end{array}$ & & & & & & $\checkmark$ & $\checkmark$ \\
\hline $\begin{array}{l}\text { She wants to prevent } \\
\text { one person from } \\
\text { contacting her online }\end{array}$ & $\checkmark$ & & & $\checkmark$ & $\checkmark$ & & \\
\hline $\begin{array}{l}\text { She wants to hide } \\
\text { the posts of one of } \\
\text { her contacts }\end{array}$ & $\checkmark$ & $\checkmark$ & $\checkmark$ & $\checkmark$ & $\checkmark$ & & $\checkmark$ \\
\hline $\begin{array}{l}\text { She does not want to } \\
\text { share her posts with } \\
\text { one of her contacts }\end{array}$ & & $\checkmark$ & $\checkmark$ & & & & $\checkmark$ \\
\hline
\end{tabular}




\subsection{Unresponsiveness}

Unexpectedly, most participants mentioned employing the common practice of keeping the unwanted requests pending for their profile, especially when they knew the person offline, not by using the Not Now or Delete Request feature but simply by leaving the request unanswered, as mentioned by P8 in Excerpt 3.

P8: Normally, what I do is just to leave it there.

Moderator: To leave it pending without

rejection?

P8: Yeah, to leave it pending forever. [Excerpt 3, Group 4]

Unresponsiveness was related to unsociability in the sense that some participants avoided action in order not to produce awareness cues of their unsocial behaviours, especially for somebody they know offline. Moreover, participants used ambiguity for creating a personal space and attempted to influence how others account for their actions (Aoki and Woodruff 2005; Hancock et al. 2009).

Most participants found it rude or impolite to avoid responding to personal conversations or not to reciprocate attempts to establish a mutual connection over a communication tool such as Facebook's Chat. Still, not all participants considered unresponsiveness to fit the description of being unsocial, since they considered this behaviour related to context. This is illustrated by two participants in Excerpt 4.

\section{P7: Yes. With chatting, [it] also happens that I don't want to reply, especially when I don't want to... Even when I don't want or when I don't have time. So, yeah. \\ P6: I would say that I do consider it a little antisocial [...]. I do make it a point to reply to all my e-mails [Private Messages] [...]. I just want to be in touch with the people I want to be in touch, and polite to the persons I don't. [Excerpt 4, Group 3]}

Additionally, some participants stated that a lack of response on Facebook may carry a certain degree of ambiguity and, therefore, admit other possible explanations. This context-related ambiguity and accountability is illustrated in Excerpt 5.

P10: The last time I sent a message through Facebook, but I didn't receive a reply back... or I knew that the person didn't reply... I don't know why, but I thought maybe they are busy, or had no Internet. [Excerpt 5, Group 4]

\subsection{Perceiving unsocial behaviours and features}

Participants consistently described two kinds of features: the "hard" and "soft" unsocial features. We found that people perceived these two kinds of features, particularly in terms of the awareness cues produced and the privacy boundaries they set. The subsections that follow describe how using the hard and soft unsocial features support unsociability

\subsubsection{Soft unsocial features}

Unsubscribe, Lists, and Privacy Settings were described as soft unsocial features by the participants. They are used mostly as "selfboundaries" (Altman 1977) of privacy; they apply directly to the profile of the user. Table 4 gives an outline of these features.

Table 4: Soft unsocial features of Facebook.

\begin{tabular}{|c|c|c|c|}
\hline & Unsubscribe & Lists & $\begin{array}{l}\text { Privacy } \\
\text { Settings }\end{array}$ \\
\hline $\begin{array}{l}\text { Motive(s) } \\
\text { for use }\end{array}$ & $\begin{array}{l}\text { Filter out } \\
\text { annoying } \\
\text { content or } \\
\text { applications }\end{array}$ & $\begin{array}{l}\text { Limit the } \\
\text { content } \\
\text { shared; } \\
\text { Filter out } \\
\text { content } \\
\text { from } \\
\text { others }\end{array}$ & $\begin{array}{l}\text { Break } \\
\text { connections; } \\
\text { Limit the } \\
\text { content } \\
\text { shared and } \\
\text { received }\end{array}$ \\
\hline $\begin{array}{l}\text { Perception } \\
\text { of feature }\end{array}$ & $\begin{array}{l}\text { Widely } \\
\text { adopted, } \\
\text { since use is } \\
\text { easy and } \\
\text { seamless }\end{array}$ & $\begin{array}{l}\text { Sorting of } \\
\text { contacts } \\
\text { can be } \\
\text { annoying }\end{array}$ & $\begin{array}{l}\text { Overkill for } \\
\text { avoiding } \\
\text { others; } \\
\text { Socially } \\
\text { accepted }\end{array}$ \\
\hline $\begin{array}{l}\text { Privacy } \\
\text { boundaries }\end{array}$ & $\begin{array}{l}\text { Self- } \\
\text { boundary }\end{array}$ & $\begin{array}{l}\text { Self- } \\
\text { boundary }\end{array}$ & $\begin{array}{l}\text { Self- } \\
\text { boundary }\end{array}$ \\
\hline $\begin{array}{l}\text { Awareness } \\
\text { cues }\end{array}$ & Reduced & Reduced & High \\
\hline
\end{tabular}

In general terms, participants had a positive attitude towards them. That is, no awkward or unpleasant social situation was described as arising after their use. Furthermore, the outcome of use of these features can be easily controlled and reverted, so returning to a previous state is easy, as described by P6 in Excerpt 6.

P6: I have used this [Unsubscribe] feature. Because I had a Friend that was very active on Facebook. And she was doing something on FarmVille or some other quizzes, so my Wall was full of her posts of those features [...]. So I used this feature to temporarily not see her updates because there are so much. [Excerpt 6 , Group 3]

In this context, participants use restrictive privacy settings to deny access deliberately, preventing others from seeing content or interacting with them online (for instance, by not allowing access to their Wall). These features allow users to "build a barrier" for their profile, to prevent a Friend from contacting them, as the participant quoted in Excerpt 7 describes.

P7: Only a few people can see my pictures [because of restrictive privacy settings] [...]. Just because I don't want it. Because I have over 400 contacts and of those, maybe there are like, if I 
say 30 it's probably too many, of my very close friends. [Excerpt 7, Group 3]

\subsubsection{Hard unsocial features}

The features Report/Block, Unfriend, and Not Now/Delete Request were consistently described as harsh or impolite, mainly because they are used as a "dyadic" privacy boundary (Altman 1977) directly to elude another person. Moreover, while the system does not actively notify about usage of these features, participants described them as producing a large number of awareness cues for others to detect that they have been used. These features were understood as permanent actions, in that reverting their outcome would involve direct awareness on the part of the targeted person, as in having to re-send a Friend Request. Table 5 provides an outline of the hard unsocial features.

Table 5: Hard unsocial features of Facebook.

\begin{tabular}{|c|c|c|c|}
\hline & $\begin{array}{l}\text { Report/ } \\
\text { Block }\end{array}$ & Unfriend & $\begin{array}{l}\text { Not Now/ } \\
\text { Delete } \\
\text { Request }\end{array}$ \\
\hline $\begin{array}{l}\text { Motive(s) } \\
\text { for use }\end{array}$ & $\begin{array}{l}\text { Breaking } \\
\text { connections; } \\
\text { Wishing to } \\
\text { limit content } \\
\text { from others }\end{array}$ & $\begin{array}{l}\text { Not being in } \\
\text { contact any } \\
\text { longer } \\
\text { (online and } \\
\text { offline); } \\
\text { Wishing to } \\
\text { limit content } \\
\text { from others }\end{array}$ & $\begin{array}{l}\text { Not wanting } \\
\text { to establish } \\
\text { a connection }\end{array}$ \\
\hline $\begin{array}{l}\text { Perception } \\
\text { of feature }\end{array}$ & $\begin{array}{l}\text { Permanent; } \\
\text { Seen as } \\
\text { harsh by } \\
\text { some; } \\
\text { Confusing } \\
\text { with regard } \\
\text { to its } \\
\text { capabilities }\end{array}$ & $\begin{array}{l}\text { Permanent; } \\
\text { Seen as } \\
\text { harsh by } \\
\text { some }\end{array}$ & $\begin{array}{l}\text { Harsh if } \\
\text { offline } \\
\text { relations } \\
\text { exist; } \\
\text { Better to } \\
\text { leave things } \\
\text { pending }\end{array}$ \\
\hline $\begin{array}{l}\text { Privacy } \\
\text { boundaries }\end{array}$ & $\begin{array}{l}\text { Dyadic } \\
\text { boundary }\end{array}$ & $\begin{array}{l}\text { Dyadic } \\
\text { boundary }\end{array}$ & $\begin{array}{l}\text { Dyadic } \\
\text { boundary }\end{array}$ \\
\hline $\begin{array}{l}\text { Awareness } \\
\text { cues }\end{array}$ & High & High & $\begin{array}{l}\text { Reduced } \\
\text { (Not Now) } \\
\text { High (Delete } \\
\text { Request) }\end{array}$ \\
\hline
\end{tabular}

Since these features were considered by some participants to be harsh, permanent, and severe, they avoided their use. For instance, in Excerpt 8:

P5: Don't know why I didn't ever [unfriend somebody]. There's some people I just left on the block list, like 5-6 people. I could have easily unfriended them, and I didn't for some reason. Maybe I was just lazy, or maybe I think it would be a little rude. [Excerpt 8, Group 2]

\section{DISCUSSION}

Participants in this study, much as other users of social technology do (Ackerman 2000; Johnson et al. 2012), adapted the systems to meet their needs. People tend to guide their interactions on SNSs by means of their own understanding of the site instead of its technical affordances.

In general terms, unsociability is an integral part of "being social": with the SNS platforms, people use the unsocial features to manage their selfpresentation and privacy concerns, applying their personal understanding of the social norms as the basis for their actions. In this section, we discuss the implications of the social-over-technical pattern seen with Facebook.

\subsection{Social-over-technical pattern: implications}

Participants used (or avoided using) the unsocial features of Facebook to "save face" while balancing an online network of people they know offline. People attempt to present themselves on SNSs as socially desirable individuals (Bryant and Marmo 2012; Zhao et al. 2008). For this, users decide what is acceptable to do in a social situation online in accordance with their personal and social understanding of the relevant social norms (Bryant and Marmo 2012; Hancock et al. 2009; Lampinen et al. 2011). Likewise, participants decide what features to use in view of their social understanding of the site and in consideration of the social norms.

Since the soft unsocial features are used without affecting other users, they made it easier for some participants to regulate their privacy. On contrary, hard unsocial features apply directly to the target profile. They guarantee safety but could be perceived as face-threatening.

When we consider the participants in our study in terms of the concept of face-work, we can point to two broad social considerations they brought up when it comes to being unsocial and interpreting the outcomes of these actions: 1) keeping the unsocial interactions as positive and discreet as possible and 2) not taking these interactions "too seriously" or "too personally."

For instance, participants exercised face-work by "storing" unwanted Friend Requests: keeping them pending instead of rejecting them. While trying to maintain personally acceptable face-work, they help others do the same. Mary stores Tim's Friend Request in an attempt to keep Tim from feeling awkward upon noticing that the request he sent was rejected. This is illustrated in Excerpts 9 and 10.

P7: Maybe denying the [Friend] request is such a harsh move in social circles that they [Facebook] don't want to force us to do it. So "Not Now" is just like a way to put it in the corner and not think about it. [Excerpt 9, Group 3]

$P 9$ : The thing is, with the new features, is not necessary to remove the person so he doesn't feel bad, so you just remove all the updates from them. So you don't need to Unfriend. So I think 
Facebook is helping us to be unsocial in a polite way. [Excerpt 10, Group 4]

Likewise, people have a "repertoire of face-saving practices" (Goffman 1967). People prefer to believe that unsocial events are not personal or spiteful acts, especially if directed towards them. That is, they seem to look for face-saving alternatives to rationalize the unsocial event - e.g. "he may not be on the site often" - instead of interpreting the action as an attack directed at them personally, as in "he does not want me as his Friend."

\subsection{Awareness cues and unsocial events}

Awareness is maintaining an overview of what others are up to (Erickson and Kellogg 2000). Awareness can be gained with system cues that inform about people's presence or activities in a shared environment. Facebook does not actively notify their users when an unsocial event has taken place, e.g. when they get a Friend Request declined. Nevertheless, as mentioned by our participants (such as $\mathrm{P} 1$ in Excerpt 11) and stated in previous research (Kwak et al. 2011; Lampinen et al. 2011; Bevan et al. 2012), users perceive certain system cues that make it possible for them to find out that the unsocial event took place. One such cue appears when the Add Friend button is reactivated.

P1: ...I remember once I look at my own profile to see what I was sharing, and I notice that I had 110 Friends exactly, and a week later, I went to see for some reason and I had 109. And I say: "Should I go through all my Friends to see who has unfriended me?" But no, I didn't [laughs]. [Excerpt 11, Group 1]

Like Kwak et al. (2011), we found that participants preferred to avoid creating awareness cues of their unsocial behaviours, especially when directed toward somebody they know offline. To this end, participants used ambiguity for creating a personal space and trying to influence how others account for their actions (Aoki and Woodruff 2005).

This is exemplified by the storing of unwanted Friend Requests, with participants using ambiguity to create "plausible deniability" (Aoki and Woodruff $2005)$ in relation to rejection. When the Friend Request remains unanswered, an explanation can be, for instance, that "maybe he is not on Facebook very often."

In other words, participants use ambiguity for creating multiple possible explanations for their actions, reducing social difficulties and costs (Aoki and Woodruff 2005). Ambiguity helps users save face, as it allows people to influence how others account for their actions. However, what each person defines as "plausible deniability" depends on personal interpretations of social norms. The ambiguous social norms produced divergent opinions in the groups.

Ambiguity defies the principle of visibility of online behaviours, which has been regarded as one of the main design principles in social technologies (Erickson and Kellogg 2000). For some SNSs, users are eager to increase the visibility of their online interactions, for instance, to find out who accesses the content they share (Bernstein et al. 2013; Gilbert 2012). However, when unsociability is involved, increased visibility may have undesired results.

Almost all of our participants expressed strong disapproval of being notified about unsocial behaviours. That is, they expected Facebook to support ambiguity in some interactions, so that they can engage in denial in plausible ways. Thus it is that even though visibility of online behaviours can be a valuable tool for some situations, such as evaluation of what content to share on the basis of its novelty and impact for their audience (Bernstein et al. 2013; Gilbert 2012), the same does not apply for unsocial behaviours. Unsocial behaviour concerns are interpersonal, and announcing them in larger circles would not be desirable.

\subsection{Reflections on the study}

The findings of this study provide a solid grounding for further research. To begin with, we relied on the seven avoidance behaviours (Bryant and Marmo 2010) as a starting point for our definition of the unsocial behaviours; these behaviours need to be attested to with further study.

Our study did not include participants with a background other than well-educated, relatively young urban person. Likewise, the absence of an adequate gender balance among participants could represent a limitation. We gathered and analyzed qualitative data and the results are expressed in terms of opinions of users, which may not represent actual behaviours. Nevertheless, we do not suggest that the behaviours we found are the only ones but they are a proof of concept: the participants have needs for and perceptions of SNS features supporting unsociability.

While other SNS platforms such as Linkedln and Twitter were briefly discussed in the focus groups, they fall out of the scope of this paper. Our first impression is that the purpose of the site seems to matter when talking about unsocial behaviours. This is consistent with previous literature, that has described that while deleting social connections is a common behaviour over Facebook and Twitter, on Facebook it can be done for personal reasons, but on Twitter it is mostly done to limit content (Bevan et al. 2012; Kwak et al. 2011; Sibona and Walczak 2011). This is illustrated in Excerpt 12. 
P9: I had stopped following people on Twitter, maybe because of the frequency and content of the tweets.

P10: Yeah, me too.

P9: Some people use Twitter as some kind of blog of 140 characters. [Excerpt 12, Group 4]

\section{DESIGN CONSIDERATIONS}

People tend to follow a social-over-technical pattern on Facebook. Ackerman (2000) emphasized an analogous "social-technical gap," a mismatch between social requirements and what systems are capable of doing. In this context, people adapt the systems to their needs, expecting both to address privacy concerns and to maintain face. We propose three general design considerations for these systems to meet the social needs behind unsociability.

\subsection{Incorporate unsocial behaviours into the design}

Facebook constantly reminds people of ways to be social through the site, such as with the Friend Suggestions feature. Less attention is paid to reminding or informing people of ways to revert social interactions. We propose integration of context-sensitive information on unsocial features in two ways. The first is to add contextual "tool-tips" for the unsocial features. While the current version of Facebook does provide context-sensitive information for some features, this is not implemented consistently throughout the site and tends only to remind users of ways to be social. Similar context-sensitive information should be employed to facilitate unsociability.

Second, we suggest providing context-sensitive information and a "Learn More" link, pointing to the Help Centre, in the dialog windows for the unsocial features, as illustrated in Figure 2, where we have added these to the current Unfriend dialog.

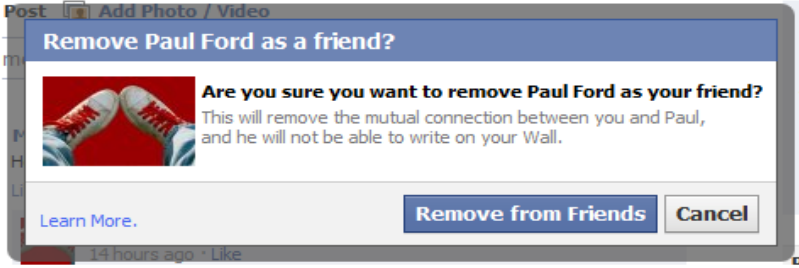

Figure 2: Proposed Unfriend dialog help.

With context-sensitive information on the unsocial features, users can figure out how to proceed when they are unsure about the capabilities of the features. Moreover, it would enable them to keep up to date on the capabilities of the system more easily. The need for this is clear: even frequent users of the site (such as P2 and P3 in Excerpt 13) are not always aware of the system capabilities.
P3: ...unsubscribe is the same like blocking, I'm not sure if there is a difference.

P2: Would it apply to the messages, the Private Messages?... OK. Yeah, maybe still... I'm not sure. [Excerpt 13, Group 1]

\subsection{Provide flexible and reversible unsocial features}

People switch gracefully among states; systems do not (Ackerman 2000). For instance, the binary mechanism to indicate social connections on SNSs has no "in-between" state as friendships do in real life. Therefore, people use (or avoid using) unsocial features to switch between states, matching their actions with their social understanding of the site.

We suggest implementing a "soft" version of Unfriend, to give users the ability to reduce their network size without feeling rude or harsh to others. This could be done by implementing a "Disconnecf" feature that places an invisible selfboundary between users, so that they mutually stop sharing and receiving content but continue to be listed as Friends. In other words, this feature would be a sort of two-way Unsubscribe.

After using the Disconnect feature, users would still be able to perform personal communications and have the option of "reconnecting" at any time, given that a mutual relationship still exists. Implementation of this feature would add to users' options for managing their privacy and self-presentation without providing greater awareness cues to others.

\subsection{Remember that people don't always want to be social}

We argue that SNS developers should apply the assumption "people do not always want to be social" as a default when designing unsocial features. For instance, Facebook designers should consider the existence of the various social practices used to elude people and should support users when they simply do not want to be social. To illustrate the importance of assuming this design policy, we describe two common unsocial behaviours that currently are not adequately supported by Facebook: storing unwanted Friend Requests and ignoring Chat messages.

People store unwanted Friend Requests to reduce the unpleasantness and social costs of rejecting someone they know offline. A consequence of this is the application of Facebook's "assumption" while a request is pending action that the two users are connected in some way. Therefore, when a user stores a request, Facebook lists their public updates on their News Feed, even if the connection has not been accepted. Secondly, Facebook recently introduced the Seen functionality to its Chat. With this new feature, users get notified 
whenever a Friend reads a chat message they have sent. This new functionality does not allow users simply to ignore a message: the sender would notice that his message was read but ignored. The Seen functionality cannot be deactivated.

The problem with the current design of these features is that they do not allow users to be "interactionally unresponsive" (Aoki and Woodruff 2005), to leave contacts pending and take no action. The problem emerges when the system assigns a meaning to unresponsiveness and, more importantly, communicates it to the targeted person. Therefore, to support these unsocial behaviours better, Facebook should let users be ambiguous.

Using ambiguity, people try to untie their true actions from the observed result, so that their behaviours can admit multiple interpretations (Aoki and Woodruff 2005; Hancock et al. 2009). Therefore, as recommended already by Lederer et al. (2004), designers of social technologies should beware inhibiting these existing social practices. Even though the design concept of "ambiguity" is not often taken up by interaction designers, in this case, ambiguity would reduce the social costs of unsocial behaviours. That is because it is up to the targeted person, not the system, to give meaning to the unsocial behaviour.

\section{CONCLUSION AND FUTURE WORK}

Our research approach has been qualitative, and we have shown with the help of focus group interviews that people engage in unsocial events both as initiators and targets. It is equally important to study both sides, and not just the avoidance strategies or privacy and self-presentation concerns of the initiator.

Focus group interviews proved to be an appropriate research method for this study. Discussion in the four focus groups "took off," with participants being eager to share and consider their opinions about unsociability, this without much involvement of the moderator. Participants attempted to build a common understanding of system features. For instance, to define Report/Block, participants collaborated to match elements of their individual personal experiences and create a fuller sense of how the feature works, each describing it from his own understanding of the functionality.

For tackling a soft topic such as unsocial behaviours, talking to a group of strangers in a confidential environment helped participants to share their experiences. As everyone mentioned to have faced similar situations, such as getting a Friend Request rejected, empathy was generated within the groups. This feeling of "not being alone", as well as approaching sensible issues via scenarios first enabled in-depth discussion.

We uncovered practices and perceptions of people engaging in unsocial events. The social-overtechnical pattern of Facebook use indicates that people use (or avoid using) the unsocial features in accordance with their social understandings rather than in view of the technical capabilities of the features. People follow this pattern to save face and manage their privacy. Accordingly, participants favoured soft unsocial features, which enable users to place a self-boundary around them and produce a minimum of awareness cues out of their unsocial behaviours. In contrast, hard unsocial features place a dyadic boundary, directly involving the targeted person. Therefore, participants considered hard features to impose increased social costs.

The next step in our research is to expand the study into other social network sites such as Linkedln and Twitter. Another direction is to explore the phenomenon with a larger number of participants.

We claim that it is vital to understand and support unsocial behaviours as a mechanism for satisfying underlying social needs, such as those for privacy and self-presentation management. Support for unsociability helps to encourage and facilitate social interactions over SNSs. This support is even more important as SNSs continue to grow and persist over time.

The unsocial features should be silent, flexible, and easy to use. In addition, designers should remember that people do not always want to be social and that they have established practices that should be respected and supported, such as using ambiguity to reduce accountability for their actions. Supporting unsociability will allow users to save face and address privacy concerns as their social needs dictate.

\section{ACKNOWLEDGEMENTS}

We thank all the volunteer participants. The first author gratefully acknowledges CONACYT funding that allowed her to focus on her studies and on the M.Sc. thesis project on which the work described in this paper is based. We thank Asko Lehmuskallio for feedback on our work.

\section{REFERENCES}

Ackerman, M.S. (2000) The intellectual challenge of CSCW: The gap between social requirements and technical feasibility. Human-Computer Interaction, 15 (2), 179-203. 
Altman, I. (1977) Privacy regulation: Culturally universal or culturally specific? J. of Social Issues 33 (3), 66-84.

Aoki, P. and Woodruff, A. (2005) Making space for stories: Ambiguity in the design of personal communication systems. In Proc. of the SIGCHI Conf. on Human factors in computing systems CHI'05, Portland, OR, 02-07 April 2005, pp. 181-190. ACM Press, New York.

Bernstein, M.S., Bakshy, E., Burke, M., and Karrer, B. (2013) Quantifying the invisible audience in social networks. In Proc. of the SIGCHI Conf. on Human factors in computing systems CHI'13, Paris, France, 27 April-02 May 2013, pp. 21-30. ACM Press, New York.

Bevan, J.L., Pfyl, J., and Barclay, B. (2012) Negative emotional and cognitive responses to being unfriended on Facebook: An exploratory study. Computers in Human Behavior 28 (4), 1458-1464.

boyd, d. (2010) Social network sites as networked publics: Affordances, dynamics, and implications. In: Papacharissi, Z. (ed) A networked self: Identity, community, and culture on Social Network Sites, pp. 39-58.

Bryant, E.M. and Marmo, J. (2010) Relational maintenance strategies on Facebook. Kentucky Journal of Communication. Available from http://kycommunication.com/jenniferpdf/Bryant.p df (4 April 2013).

Bryant, E.M. and Marmo, J. (2012) The rules of Facebook friendship: A two-stage examination of interaction rules in close, casual, and acquaintance friendships. J. of Social and Personal Relationships 29 (8), 1013-1035.

Canary, D.J., Stafford, L., Hause, K.S., and Wallace, L.A. (1993) An inductive analysis of relational maintenance strategies: Comparisons among lovers, relatives, friends, and others. Communication Research Reports 10 (1), 3-14.

Erickson, T. and Kellogg, W.A. (2000) Social translucence: An approach to designing systems that support social processes. ACM TOCHI 7 (1), 59-83.

Gilbert, E. (2012) Designing social translucence over social networks. In Proc. of the SIGCHI Conf. on Human factors in computing systems CHI'12, Austin, TX, 05-10 May 2012, pp. 27312740. ACM Press, New York.

Goffman, E. (1967) Interaction ritual: Essays in face-to-face behaviour. Aldine Publishing, Chicago.

Hancock, J., Birnholtz, J., Bazarova, N., Guillory, J., Perlin, J., and Amos, B. (2009) Butler lies: awareness, deception and design. In Proc. of the SIGCHI Conf. on Human factors in computing systems CHI'09, Boston, MA, 04-09 April, 2009, pp. 517-526. ACM Press, New York.

Johnson, M., Egelman, S., and Bellovin, S.M. (2012) Facebook and privacy: It's complicated. In Proc. of the Eighth Symposium on Usable Privacy and Security SOUPS'12, Washington, DC, 11-13 July 2012. ACM Press, New York.

Kwak, H., Chun, H., and Moon, S. (2011) Fragile online relationship: A first look at unfollow dynamics in Twitter. In Proc. of the SIGCHI Conf. on Human factors in computing systems CHI'11, Vancouver, Canada, 7-12 May 2011, pp. 1091-1100. ACM Press, New York.

Lampinen, A., Lehtinen, V., Lehmuskallio, A., and Tamminen, S. (2011) We're in it together: Interpersonal management of disclosure in social network services. In Proc. of the SIGCHI Conf. on Human factors in computing systems CHI'11, Vancouver, Canada, 7-12 May 2011, pp. 3217-3226. ACM Press, New York.

Lederer, S., Hong, I., Dey, K., and Landay, A. (2004) Personal privacy through understanding and action: Five pitfalls for designers. Personal and Ubiquitous Computing 8 (6), 440-454.

Oxford Dictionaries (2013a) Definition of antisocial in Oxford Dictionaries (British \& World English). Available from http://oxforddictionaries.com/ definition/english/antisocial (4 April 2013).

Oxford Dictionaries (2013b) Definition of unsociable in Oxford Dictionaries (British \& World English). Available from http://oxforddictionaries.com/ definition/english/unsociable (4 April 2013).

Sibona, C. and Walczak, S. (2011) Unfriend of Facebook: Friend request and online/offline behavior analysis. In Proc. of the $44^{\text {th }}$ International Conference on System Sciences HICSS'11, Hawaii, 04-07 January 2011, pp. 110. IEEE Computer Society, Washington, DC.

Stewart, D.W., Shamdasani, P.N., and Rook, D.W. (2007) Focus Groups: Theory and Practice (2nd edition). Sage Publications, Thousand Oaks, CA.

Zhao, S., Grasmuck, S., and Martin, J. (2008) Identity construction on Facebook: Digital empowerment in anchored relationships. Computers in Human Behavior 24 (5), 18161863.

Zimmer, B. (2009) On Language: The age of undoing. Blog entry, 15 Sep 2009, New York Times. Available from http://www.nytimes.com/ /09/20/magazine/20FOB-onlanguage-t.html (3 April 2013). 